\title{
Focus on the Enterprising Researcher to Sustain Research Universities
}

\author{
Kimberly Andrews Espy \\ Charles Bessey Professor, Associate Vice Chancellor for Research \& Acting \\ Dean of Graduate Studies, University of Nebraska-Lincoln
}

The national conversation about sustaining research universities has focused
primarily on changes to federal policies. Several papers in this volume success. From the perspective of the individual researcher though, sustaining research universities is fundamentally about actions that initiate, enable, and enhance the research enterprise, coupled with those that reduce barriers that get in the way. What is the research enterprise? Fundamentally, the research enterprise is defined by enterprising researchers. With that term, researchers means faculty scholars from all disciplines, where the common denominator is creating something new, be it a book, a performance, an article, a method, a product, or knowledge.

The microcosm of the enterprising researcher can be characterized by four tenets:

- Diverse, Flexible, and Unfettered Pursuit,

- Creativity, Originality, and Innovation,

- Impact, and

- Transformation.

Therefore, in addition to changing national policies and positioning the university for greater competitiveness, complimentary effort to foster the "enterprising" nature at the level of the researcher is an important, but somewhat neglected, facet of sustaining research universities. Enabling researchers to be able to chase down a "harebrained" idea, to debunk conventional thinking, to develop the alternative method or approach, which impacts national needs and transforms the field is the key feature of a vibrant, sustainable research university.

What can we do differently to spark and sustain the "enterprising"?

Systematic Selection. Current practices for hiring faculty have not changed substantially in decades, and yet the availability of well researched, valid information on how to effectively recruit, select, and hire has burgeoned. All major research universities are trying to identify and select those faculty who want to receive "tenure for work", and not hire those who "work for tenure". Yet, most departments write generic advertisements and passively place them in standard venues, without targeted outreach and recruitment. 
Furthermore search committees pore over vitae and positive letters of recommendation, to glean marginal differences in the number of publications or the degree of enthusiasm of the referee. Unfortunately, there is little systematic evaluation of candidate attributes such as motivation, diligence, work ethic, or skills like team building, collaboration, and communication. The research enterprise has changed, gone are the days where a scientist sits in the laboratory in isolation. In order to sustain the enterprise, updated hiring methods to directly assess the enterprising qualities of candidates, and more systematically consider these characteristics in selection, would benefit institutions broadly.

Time to Think. To develop the "out of the box" idea, researchers need time to be enterprising, - to read outside of their area, explore using different tools and instruments, play around with different methods to investigate unchartered areas and envision new applications. In the last decades, the increased demands placed on faculty are not uniformly distributed. Research active faculty at major research universities have stepped up their game in the ever increasingly competitive climate. Researchers are submitting more applications, writing more papers, and training more students. However, the expectations for service and teaching for faculty who are more focused on these important endeavors largely has not changed. At many institutions apportionment is sacrosanct, and once set, does not typically change, despite the variation in interests, skills, and impacts of different faculty and changes in these across a career. Apportioning faculty responsibilities to best fit skills and interests in a dynamic, flexible manner undergirds an enterprising, sustainable institution.

Reduce Barriers. Researchers spend a lot of time doing tasks other than teaching, service, and research. As the research enterprise has become more complicated, the demands for research compliance and project management has increased. Institutions can do a lot to minimize burden - by retaining adequate funds and providing staff for budget and proposal assistance. Some universities have programs for more centralized assistance with project management and human resources. Typically, researchers are not enthusiastic managers - being free of such concerns is partly why many chose to become university faculty rather than selecting other professional careers outside of academe. Providing full service help supports faculty, who are then less fettered by such concerns and have more time and energy to devote to doing research. By always keeping the perspective of doing research (and not of counting beans or fearing lawsuits), the University of Nebraska-Lincoln, for example, has done relatively small things, like providing electronic forms, pre-populated fields, and remote, 24hour access, which have made a difference in the perceived hassle by researchers that can easily dampen any enterprising spirit.

Invest in Ideas. Today's challenges - such as energy, climate change, water, human health - likely will not be "solved" by a single investigator from one discipline toiling in a laboratory. 
These problems are simply too big, multi-factorial, and entrenched. Sustaining the research enterprise fosters interactions and collaborations among researchers from various disciplines, who have different perspectives, training and methods, but share a common commitment to the problem or question at hand. Research centers have been the engine of innovation, leveraging individual investigator success and lacing it together in new ways that are greater than the sum of the parts. Such environments allow enterprising faculty to pursue unconventional ideas, use new methods, and have a broader and more transformative impact. The challenge, of course, for the institution is in continuing to strategically invest in existing strengths, while keeping an open and nimble mind to spot new opportunities that can flourish with attention and capital. The University of Nebraska-Lincoln, for example, has several research centers that "make sense" given the geography and history of our state - Nebraska Center for Energy Sciences Research, Water for Food Institute, Center for Plant Sciences Innovation, and the Nebraska Transportation Center. However, the university has realized substantial growth in other areas that contribute importantly to the sustainability of the enterprise, such as the Nebraska Center for Materials and Nanoscience, and also drive economic development in the state.

Feed our Future. Commitment to high quality graduate education is the foundation for sustainable impact of any research university in the long term.
Graduate students often are the "glue" that make interdisciplinary work happen, they learn new methods and bring them into the lab, and go on to propagate the "enterprising" as the next generation of scholars. Yet, graduate study is under subtle attack. Declining budgets result in reduced graduate assistantships, and inequities in the funding model make it more cost effective to hire a technician or postdoctoral fellow than train a graduate student. Irrational drivers of supply and demand lead to admitting a large number of "unfunded" graduate students in some disciplines, and the necessity to obtain support prolongs time to degree. This practice artificially inflates demand that does not match hiring prospects after degree attainment. These realities are in stark contrast to the national conversation centered on the new "knowledge / information economy", where the demand for technically skilled, advanced credentialed individuals has never been higher. Nationally, research universities have been urged to expand capacity to train more graduate students in the enterprising ways to meet national competitiveness goals. Professors of Practice positions that focus on enterprising instruction and impact have been used successfully to alleviate some of the instructional demand drivers, while enhancing teaching quality. However, the system of graduate student support needs rethinking, with a greater partnership by the federal government. Unfortunately, states or donors do not have the same interests in providing financial support for graduate students as for undergraduates, and yet sustainable models for graduate study are key 
element of the research enterprise and strengthening research universities.

In summary, the research university is a direct reflection of its enterprising faculty scholars. Research universities are something less without innovative researchers pursuing new avenues that might be the next light bulb, model $\mathrm{T}$, microchip, or MRI. Working from the microcosm of the researcher is an important perspective to remember in considering efforts to sustain research universities. 